CrossMark \& clickfor updates

Cite this: Mol. BioSyst., 2015, 11, 1708

Received 9th January 2015, Accepted 14th April 2015

DOI: $10.1039 / c 5 m b 00020 c$

www.rsc.org/molecularbiosystems

\section{Comparative membrane proteomics: a technical advancement in the search of renal cell carcinoma biomarkers $\dagger$}

\author{
Francesca Raimondo, ${ }^{* a}$ Samuele Corbetta, ${ }^{a}$ Andrea Savoia, ${ }^{a}$ Clizia Chinello, ${ }^{a}$ \\ Marta Cazzaniga, ${ }^{a}$ Francesco Rocco, ${ }^{\mathrm{b}}$ Silvano Bosari, ${ }^{\mathrm{C}}$ Marco Grasso, ${ }^{\mathrm{d}}$ \\ Giorgio Bovo, ${ }^{d}$ Fulvio Magni ${ }^{a}$ and Marina Pitto ${ }^{a}$
}

\begin{abstract}
Renal Cell Carcinoma (RCC) is the most common kidney cancer, accounting for 3\% of adult malignancies, with high metastatic potential and radio-/chemo-resistance. To investigate the protein profile of membrane microdomains (MD), plasma membrane supramolecular structures involved in cell signaling, transport, and neoplastic transformation, we set up a proteomic bottom-up approach as a starting point for the identification of potential RCC biomarkers. We purified MD from RCC and adjacent normal kidney (ANK) tissues, through their resistance to non-ionic detergents followed by ultracentrifugation in sucrose density gradient. MD from 5 RCC/ANK tissues were then pooled and analysed by LC-ESI-MS/MS. In order to identify the highest number of proteins and increase the amount of membrane and hydrophobic ones, we first optimized an enzymatic digestion protocol based on Filter Aided Sample Preparation (FASP), coupled to MD delipidation. The MS analysis led to the identification of 742 ANK MD and 721 RCC MD proteins, of which, respectively, 53.1\% and 52.6\% were membrane- bound. Additionally, we evaluated RCC MD differential proteome by label-free quantification; 170 and 126 proteins were found to be, respectively, up-regulated and down-regulated in RCC MD. Some differential proteins, namely CA2, CD13, and ANXA2, were subjected to validation by immunodecoration. These results show the importance of setting up different protocols for the proteomic analysis of membrane proteins, specific to the different molecular features of the samples. Furthermore, the subcellular proteomic approach provided a list of differentially expressed proteins among which RCC biomarkers may be looked for.
\end{abstract}

\section{Introduction}

Renal Cell Carcinoma (RCC) is the deadliest tumor of the genitourinary tract. Clear cell renal cell carcinoma represents the most common histotype, accounting for $70-80 \%$ of all kidney cancers. Due to its asymptomatic development, approximately $80 \%$ of RCCs are discovered incidentally during unrelated diagnostic abdominal imaging, when the disease is already in the advanced phase. $^{1,2}$ Furthermore, RCC is chemotherapy and immunotherapy resistant, and nephrectomy is the only beneficial therapy.

\footnotetext{
${ }^{a}$ Department of Health Sciences, Univ. of Milano-Bicocca, Via Cadore 48, 20900, Monza, Italy. E-mail: francesca.raimondo@unimib.it; Fax: +39 026448 8068; Tel: +390264488106

${ }^{b}$ Department of Specialistic Surgical Sciences, Urology unit, Ospedale Maggiore Policlinico Foundation, IRCCS, Milano, Italy

${ }^{c}$ Department of Medicine, Surgery and Dental Sciences, Pathology Unit, Ospedale Maggiore Policlinico Foundation Milano, IRCCS, Italy

${ }^{d}$ Department of Surgical Pathology, Cytology, Medical Genetics and Nephropathology, Azienda Ospedaliera San Gerardo, Monza, Italy

$\dagger$ Electronic supplementary information (ESI) available. See DOI: 10.1039/c5mb00020c
}

Once metastases develop, the prognosis for long-term survival is poor; the 5 year survival rate for non-treated patients is usually less than $14 \%$. Nevertheless, there are currently no circulating validated biomarkers able to confirm the identity of renal masses, whether benign or malignant. ${ }^{3,4}$

Plasma membrane proteomics seems to be a promising tool to address this issue, as membrane proteins perform endocytosis and signaling, and modifications of plasma membrane composition are encountered in several cancers. ${ }^{5,6}$ Moreover, about two-thirds of membrane proteins are drug targets, hence crucial for therapy advancement.

In particular, within the membrane, there are specialized microdomains, also known as lipid rafts. Membrane microdomains (MD) are small (10-200 nm), heterogeneous, highly dynamic, sterol- and sphingolipid-enriched lateral assemblies that compartmentalize cellular processes. Caveolae, a subclass of such MD, are flask-like invaginations of the plasma membrane that characteristically display caveolin-1 expression. ${ }^{7}$

MD are highly dynamic structures and act as selective signal transduction mediators, enabling interactions between the 
intra- and extra-cellular compartments. Furthermore, they play a key role in drug resistance, cell migration, cell adhesion, and cell survival, as well as in metastasis and tumor progression. ${ }^{8-11}$ Since membrane microdomains represent a minor and highly selected subset of the cellular proteome, they are particularly well suited to investigation using MS techniques. However, their peculiar lipid composition and the enrichment in highly hydrophobic membrane proteins make the assessment of the microdomain proteome a hard issue to address, therefore requiring the optimization of specific protocols. In fact, membrane proteins are usually under-represented in classical proteomic approaches relying on 2D gel electrophoresis (2DE) and MS analysis. This is due to them being generally not very abundant, their isoelectric points (pIs) being generally alkaline and their solubility in the aqueous buffers used for isoelectrofocusing (IEF) being poor. ${ }^{11-13}$ Recent data on the quantitative proteomics of MD - lipid rafts or caveolae have underlined the puzzling role of various signaling proteins in cancer development, but these studies were mainly performed on neoplastic cell lines. ${ }^{14-17}$ However, procedures commonly used for cell cultures, such as metabolic labelling, are not suitable for the study of human tissue MD, making label-free quantification a valid choice to achieve differential expression profiles. Moreover, the protocol needs to be adapted to small amount of samples, as feasible when working with human surgical specimens.

For these reasons, starting from human surgical samples, we focused on the pre-analytical phase of sample preparation, in order to improve the identification of MD membrane proteins, using a gelfree approach through liquid chromatography coupled to tandem mass spectrometry (LC-MS/MS). We evaluated three different digestion protocols based on the Filter Aided Sample Preparation (FASP) technique, and, after optimization, we assessed differential RCC MD proteomes by label-free quantification, as a starting point for the identification of potential RCC biomarkers.

\section{Materials and methods}

\section{Chemicals}

Solutions were prepared with Milli-Q water. Water of HPLC grade, trifluoroacetic acid (TFA), isopropyl alcohol, tributyl phosphate (TBP), ammonium bicarbonate (ABC), dithiothreitol (DTT), iodoacetamide (IAA), urea, Triton X-100, Tween-20, Trizma-base, MES, sucrose, BCA protein assay reagent and BSA were from SIGMA Chemical Co. (St. Louis, MO, USA). Acetonitrile (ACN), methanol, and glycerol were from Merck (Darmstadt, Germany). Porcine trypsin was from Promega (Madison, WI, USA). Bradford proteinbinding colorimetric assay was purchased from Bio-Rad (Hercules, CA, USA). Anti-protease inhibitor cocktail (Complete) was from Roche (Monza, Italy). NuPAGE ${ }^{\circledR}$ SDS-PAGE gel electrophoresis system components (mini gels, running and loading buffers, molecular weight markers and Coomassie brilliant blue staining-CBB) were supplied by Life Technologies (Paisley, Renfrewshire, UK). Hybond-ECL nitrocellulose membrane was from GE (Little Chalfont, Buckinghamshire, UK). Anti-aminopeptidase N (CD13) monoclonal antibody, anti-annexin A2 (ANXA2) and anti-carbonic anhydrase (CA2) polyclonal antibodies were from Abcam (Cambridge, UK).
Species-specific secondary peroxidase conjugated antibodies and ECL reagents were from Pierce (Rockford, IL, USA).

\section{Patients and specimens}

Patients with suspected RCC, not receiving any previous chemotherapy, were subjected to radical nephrectomy, after their informed consent and the local research ethics committee approval (U.O. Comitato di Etica e Sperimentazione Farmaci Direzione Scientifica Fondazione IRCCS Ca'Granda Ospedale Maggiore Policlinico, Milano). RCC was classified according to the WHO recommendations ${ }^{18}$ and the 2009 TNM (tumor-node-metastasis) system classification also using immunohistochemical techniques; only samples diagnosed as conventional clear cell RCC were included in the study. Tumor grading was performed according to the Fuhrman grading system. ${ }^{19}$

Immediately after removal, the pathologist collected samples of primary RCC, selected inside homogeneous areas and avoiding grossly necrotic or fibrotic parts, and of homologous normal cortical tissue (adjacent normal kidney, ANK) contiguous to the tumoral mass. A minimum of one $\mathrm{cm}^{3}$ of tumor and normal cortex were placed in sucrose buffered solution ( $250 \mathrm{mM}$ sucrose, $10 \mathrm{mM}$ Tris-HCl, pH 7.4, 1 mM EDTA), kept on ice and immediately transferred to the laboratory.

The clinical and personal features of the studied patients are summarized in Table 1. Their neoplasms had quite homogeneous characteristics, being in the early phase, and neither metastasis nor positive lymph nodes were present at diagnosis.

Table 1 Clear cell renal cell carcinoma samples analyzed in this study and the corresponding clinical data

\begin{tabular}{|c|c|c|c|c|c|c|c|}
\hline \multirow[b]{3}{*}{ Patients } & \multirow[b]{3}{*}{ Age } & \multirow[b]{3}{*}{ Sex } & \multirow[b]{3}{*}{ pT } & \multirow[b]{3}{*}{ G } & \multicolumn{3}{|c|}{ Membrane microdomains } \\
\hline & & & & & \multirow{2}{*}{$\frac{\text { ANK }}{\text { FASP set-up }^{a}}$} & \multicolumn{2}{|c|}{ ANK vs. RCC } \\
\hline & & & & & & FASP $^{b}$ & $1 \mathrm{DE}^{c}$ \\
\hline $45 \mathrm{DM}$ & 53 & $\mathrm{~F}$ & $1 \mathrm{~b}$ & 2 & & $\mathrm{X}$ & $\mathrm{X}$ \\
\hline $46 \mathrm{SA}$ & 67 & $\mathrm{~F}$ & 2 & 2 & $\mathrm{X}$ & & \\
\hline $47 \mathrm{CA}$ & 78 & $\mathrm{~F}$ & $1 \mathrm{a}$ & 2 & $\mathrm{X}$ & & \\
\hline 48GA & 54 & M & $1 b$ & 2 & & $\mathrm{X}$ & $\mathrm{X}$ \\
\hline 49CA & 70 & M & $3 b$ & 3 & & $\mathrm{X}$ & $\mathrm{X}$ \\
\hline $50 \mathrm{PC}$ & 51 & M & $1 b$ & 2 & & & \\
\hline 51MI & 61 & $\mathrm{~F}$ & $1 \mathrm{~b}$ & 2 & $\mathrm{X}$ & & $\mathrm{X}$ \\
\hline $52 \mathrm{CA}$ & 59 & $\mathrm{~F}$ & $2 \mathrm{a}$ & 2 & & & $\mathrm{X}$ \\
\hline $60 \mathrm{CC}$ & 78 & M & $3 a$ & 3 & & $\mathrm{X}$ & $\mathrm{X}$ \\
\hline $61 \mathrm{FG}$ & 56 & M & $1 \mathrm{~b}$ & 2 & & $\mathrm{X}$ & $\mathrm{X}$ \\
\hline 66SML & 48 & $\mathrm{~F}$ & $2 \mathrm{a}$ & 2 & $\mathrm{X}$ & & \\
\hline 70LS & 71 & M & $1 \mathrm{~b}$ & 2 & $\mathrm{X}$ & & \\
\hline $72 \mathrm{FG}$ & 59 & M & $1 \mathrm{a}$ & 2 & $\mathrm{x}$ & & \\
\hline 75CPL & 71 & M & $1 b$ & 2 & $\mathrm{X}$ & & \\
\hline $77 \mathrm{FG}$ & 70 & M & $1 \mathrm{~b}$ & 2 & $\mathrm{X}$ & & \\
\hline 80MLA & 78 & $\mathrm{~F}$ & $3 b$ & $2-3$ & $\mathrm{X}$ & & \\
\hline 91BE & 58 & M & $3 b$ & 1 & $\mathrm{X}$ & & \\
\hline 117VLF & 43 & M & 2 & 2 & $\mathrm{X}$ & & \\
\hline
\end{tabular}

pT, tumor stage; G, nuclear grade. ${ }^{a}$ Samples used for the preparation of the ANK MD pool in order to optimize the FASP protocol. ${ }^{b}$ Samples used for the label-free quantitation. ${ }^{c}$ Samples analyzed by $1 \mathrm{DE} .{ }^{20}$

\section{Subcellular fractionation and microdomain isolation}

After nephrectomy, fresh RCC and ANK tissue samples were submitted to subcellular fractionation through differential 
centrifugation; all steps were performed in a cold room $\left(4{ }^{\circ} \mathrm{C}\right)$ or on ice. Subcellular and microdomain-enriched fractions were isolated and characterized as described. ${ }^{20}$

\section{Electrophoresis and western blotting}

Protein separation was performed by the NuPAGE ${ }^{\circledR}$ electrophoresis system (Life Technologies). Equal amounts $(10 \mu \mathrm{g})$ of subcellular fraction proteins were separated by $4-12 \%$ NuPAGE and blotted onto nitrocellulose membranes using a mini tank electrophoretic transfer apparatus (Hoefer). Membranes were developed with the respective primary antibodies (anti-CD13 1:2000, anti-ANXA2 1:2000, and anti-CA2 1:1000), followed by peroxidaseconjugated secondary antibodies (Pierce) and enhanced chemiluminescence detection (SuperSignal West-Pico ECL, Pierce). Images were captured on a CCD camera, LAS4000 (GE Healthcare).

\section{Delipidation and protein precipitation by tri- $\boldsymbol{n}$-butylphosphate/ acetone/methanol}

Aliquots $(100 \mu \mathrm{L})$ of the MD pools were mixed with 14 volumes of ice-cold TBP/acetone/methanol mixture $(1: 12: 1)$ and incubated at $4{ }^{\circ} \mathrm{C}$ for 90 minutes. Proteins were precipitated by centrifugation at $2800 \times g$ for 15 minutes $\left(4{ }^{\circ} \mathrm{C}\right)$, washed sequentially with $1 \mathrm{~mL}$ of TBP, acetone and methanol, and then air-dried. ${ }^{21}$ During the set-up of delipidation experiments, we assessed a loss of MD proteins of about $20 \%$. Accordingly, we performed delipidation on $150 \mu \mathrm{g}$ of ANK and RCC MD, since $100 \mu \mathrm{g}$ of proteins were required for FASP protocols. In order to evaluate the reproducibility of protein extraction, we performed quantitative protein assay using the $\mathrm{BCA}$ reagent on delipidated samples and verified the recovery after NuPAGE/CBB staining, by loading equal aliquots of ANK and RCC MD delipidated samples.

\section{Filter aided sample preparation: protocol optimization}

Due to the peculiar MD lipid composition, we optimized an enzymatic digestion protocol based on Filter Aided Sample Preparation (FASP), ${ }^{22}$ comparing three different protocols (Table 2), with and without previous delipidation. For this purpose, equal amounts of MD isolated from ANK tissues of 11 patients (Table 1) were pooled in order to eliminate interindividual differences.

Protocol 1 was an adapted version of the FASP digestion by Wiśniewski et al., ${ }^{22}$ already reported for the MS analysis of urinary exosomes. ${ }^{23}$ The lysis of MD, about $100 \mu \mathrm{g}$ of proteins,

Table 2 FASP protocols ${ }^{a}$

\begin{tabular}{lllllll}
\hline $\begin{array}{l}\text { FASP } \\
\text { protocol }\end{array}$ & $\begin{array}{l}\text { Denaturation } \\
\text { buffer }\end{array}$ & $\begin{array}{l}\text { DTT } \\
(\mathrm{mM})\end{array}$ & $\begin{array}{l}\text { IAA } \\
(\mathrm{M})\end{array}$ & $\begin{array}{l}\text { Washing } \\
\text { buffer }\end{array}$ & $\begin{array}{l}\text { Trypsin } \\
(\mu \mathrm{g})\end{array}$ & Elution \\
\hline 1 & RIPA & 50 & 0.1 & ABC & 4 & $\mathrm{H}_{2} \mathrm{O}$ \\
2 & RIPA & 50 & 0.05 & ABC & 1 & $\begin{array}{l}\text { NaCl } 0.5 \mathrm{M} \\
\text { TFA } 0.1 \%\end{array}$ \\
3 & SDS & 50 & 0.05 & UA & 1 & $\begin{array}{l}\text { NaCl } 0.5 \mathrm{M} \\
\text { TFA } 0.1 \%\end{array}$
\end{tabular}

${ }^{a}$ ABC, $50 \mathrm{mM}$ ammonium bicarbonate buffer; UA, $8 \mathrm{M}$ urea in $100 \mathrm{mM}$ Tris- $\mathrm{HCl} \mathrm{pH} 8.5$ and $8 \mathrm{M}$ urea in $100 \mathrm{mM}$ Tris- $\mathrm{HCl} \mathrm{pH}$ 7.9; TFA, trifluoroacetic acid. was performed by a 30 min incubation in RIPA buffer $(50 \mathrm{mM}$ Tris-HCl pH 7.4, 1\% NP40, 0.25\% sodium deoxycholate, $150 \mathrm{mM}$ $\mathrm{NaCl}$, and $1 \mathrm{mM}$ EDTA). MD were then submitted to disulfide bond reduction with $50 \mathrm{mM}$ DTT in $50 \mathrm{mM} \mathrm{ABC}\left(95{ }^{\circ} \mathrm{C}\right.$ for $5 \mathrm{~min}$ ). After cooling the sample, the lysates were transferred into the ultrafiltration units (Amicon Ultra-0.5 mL $30 \mathrm{kDa}$, Millipore) and centrifuged at $14000 \times g$ for $15 \mathrm{~min}$ in order to eliminate lysis buffer and DTT. The filters were washed with $300 \mu \mathrm{L}$ of $50 \mathrm{mM} \mathrm{ABC}(14000 \times g$ for $10 \mathrm{~min})$ and the samples were incubated with $80 \mu \mathrm{L}$ of $100 \mathrm{mM}$ IAA in darkness for $30 \mathrm{~min}$. IAA was discharged by centrifugation at $14000 \times g$ for $5 \mathrm{~min}$, and the filters were washed with $200 \mu \mathrm{L}$ of $50 \mathrm{mM} \mathrm{ABC}$ five times $(14000 \times g$ for $10 \mathrm{~min})$. Proteins were digested overnight at $37{ }^{\circ} \mathrm{C}$ by $4 \mu \mathrm{g}$ of trypsin for each sample. After digestion, the filtered tryptic peptides were collected by centrifugation with two washes of water ( $40 \mu \mathrm{L}$ and subsequently $100 \mu \mathrm{L})$.

In protocol 2, lysis and reduction steps were the same as protocol 1; alkylation was performed by incubating the samples with $100 \mu \mathrm{L}$ of $50 \mathrm{mM}$ IAA in darkness for $20 \mathrm{~min}$. After IAA elimination, the filters were washed with $100 \mu \mathrm{L}$ of $50 \mathrm{mM}$ $\mathrm{ABC}$ four times $(14000 \times g$ for $15 \mathrm{~min})$. Protein digestion was performed overnight at $37{ }^{\circ} \mathrm{C}$ adding $1 \mu \mathrm{g}$ of trypsin. After centrifugation at $14000 \times g$ for $10 \mathrm{~min}$, the filtered tryptic peptides were collected, and the filters washed with $50 \mathrm{mM} \mathrm{ABC}$ and $500 \mathrm{mM} \mathrm{NaCl}$, two times each. The eluted peptides were acidified by $0.1 \%$ TFA.

In protocol 3, the sample was solubilized by a denaturation buffer containing SDS and DTT (2\% SDS, $50 \mathrm{mM}$ DTT, $50 \mathrm{mM}$ Tris-HCl pH 7.6), incubated at $95{ }^{\circ} \mathrm{C}$ for 5 minutes. Dissolved MD membranes $(70 \mu \mathrm{L})$ were mixed with $430 \mu \mathrm{L}$ of $8 \mathrm{M}$ urea in $100 \mathrm{mM}$ Tris- $\mathrm{HCl}, \mathrm{pH} 8.5$ (UA 8.5 solution), transferred into the ultrafiltration device and centrifuged at $14000 \times g$ for 15 minutes. Alkylation was performed as in protocol 2, followed by four washes, two with $8 \mathrm{M}$ urea in $100 \mathrm{mM}$ Tris-HCl, pH 7.9 (UA 7.9 solution) and two with $50 \mathrm{mM} \mathrm{ABC}(14000 \times g$ for $15 \mathrm{~min})$. Protein digestion and peptide elution were the same as protocol 2 .

\section{Digestion and peptide extraction}

MD isolated from RCC and ANK tissues of 5 patients were pooled (Table 1), and the resulting samples were lysed and subjected to protein extraction and digestion by the FASP protocol 3, after delipidation.

\section{MD proteome analysis by nLC-ESI-MS/MS}

All the MS analysis and protein identification were performed under the same conditions. Before LC-MS analysis, tryptic digests for each sample were quantitated using a NanoDrop spectrophotometer and desalted using Ziptip ${ }^{\mathrm{TM}} \mu-\mathrm{C}_{18}$ (Millipore) following manufacturer's instructions. ${ }^{24}$ About $1 \mu \mathrm{g}$ of digested proteins for each sample run were injected at least 3 times into a Dionex UltiMate 3000 rapid separation (RS) LC nanosystem (Thermo Scientific, Germany) coupled online with a nano ESI ion trap mass spectrometer, amaZon ETD (Bruker Daltonics $\mathrm{GmbH}$, Germany). After the $\mu$-trapping column desalting (Dionex, Acclaim PepMap $100 \mathrm{C} 18$, cartridge, $300 \mu \mathrm{m}$ ID $\times 5 \mathrm{~mm}$, $5 \mu \mathrm{m})$ and concentration steps, peptides were then separated 
by a 360 min-multistep gradient on the analytical $50 \mathrm{~cm}$ nanocolumn (Dionex, 0.075 mm ID, Acclaim PepMap100, C18, $2 \mu \mathrm{m}$ )

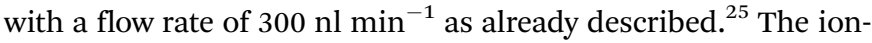
trap mass spectrometer equipped with an on-line nanospray source was operated in data-dependent-acquisition mode. For MS generation, enhanced resolution and a trap ICC value of 400000 were used; for MS/MS acquisition, the ICC target was increased to 1000 000; a narrow range for Smart Fragmentation from 50 to $150 \%$ was adopted. CID MS/MS fragmentation was set to fragment the ten most abundant MS peaks with strictly active exclusion after one spectrum and released after 9 seconds. The obtained chromatograms were elaborated using Compass DataAnalysis $^{\mathrm{TM}}$, v.4.0 Sp4 (Bruker Daltonics, Germany), and the resulting mass lists were processed using an in-house Mascot search engine (v.2.4.0), through Mascot Daemon. Database searching was restricted to the human Swissprot database (accessed Apr 2014; 544996 sequences; 193815432 residues). Trypsin as an enzyme and carbamidomethyl (C) as a fixed modification were set in search parameters. Mass tolerance for all identifications was generally fixed at $2 \mathrm{Da}$ for the precursor ions and 0.8 $\mathrm{Da}$ for the product ions. Automatic decoy database search and a built-in Percolator algorithm were applied to calculate the posterior error probabilities for each peptide-spectrum match and rescore search results with a unique significance threshold. Data were filtered using a global false discovery rate $<1 \%$ and only proteins with at least one unique identical peptide sequence $(p$-value $<0.05)$ were considered identified. ${ }^{26}$

\section{Label-free protein abundance evaluation}

Protein abundance in MD of RCC and ANK tissues was determined using Progenesis LC-MS software $\mathrm{v} 4.1$ (Non-linear Dynamics, Newcastle, England). The raw LC-MS/MS data were imported and the ion intensity maps of all runs (3 runs for each class) were visually examined for defects and used for the alignment process, performed using the "Automatic Alignment" function. One sample is thus set as the reference run and the retention times of all other samples within the experiment were automatically aligned to create a maximal overlay across the data. The default sensitivity and a peak width of 0.2 min were selected as parameters for the feature detection algorithm. Samples were then allocated to their experimental class (RCC vs. ANK). The identification of peptides was performed using an in-house Mascot search engine as described above. The filtered MASCOT search results were imported back into Progenesis LC-MS and the identified peptides with a score lower than 13 were discarded ( $p$-value $>0.05)$. Experimental variation affecting the protein expression was minimized by analyzing the same amount of sample $(1 \mu \mathrm{g})$ and by the normalization process performed using Progenesis software (http://www.nonlinear. com/progenesis/qi-for-proteomics/v2.0). Protein quantification results were exported and used for further analysis.

\section{Bioinformatic analysis}

Gene ontology (GO) analysis was performed using the LocDB database (www.rostlab.org/services/locDB/) for investigating the subcellular localization of the identified proteins and the
Protein ANalysis THrough Evolutionary Relationship (PANTHER) database (http:/www.pantherdb.org/) for the analysis of their molecular functions. In addition, membrane proteins were deeply studied and transmembrane helix prediction was performed using the online TMHMM 2.0 prediction server (http:// www.cbs.dtu.dk/services/TMHMM/), ${ }^{27,28}$ palmitoylation was predicted using CSS-Palm 2.0, ${ }^{29}$ GPI-modification site prediction was conducted through the online big-PI predictor server (http:// mendel.imp.ac.at/sat/gpi/gpi_server.html) ${ }^{30}$ and myristoylation was predicted using the online Expasy Myristoylator prediction server (http://web.expasy.org/myristoylator/). ${ }^{31}$ Protein-protein interactions were predicted using the Search Tool for the Retrieval of Interacting Genes/Proteins (STRING) database v9.0 (http://www. string-db.org/) and proteins were linked based on the following six criteria: neighbourhood, gene fusion, co-occurrence, co-expression, experimental evidence and existing databases. ${ }^{32}$

Tissue specificity of the identified proteins was evaluated using different databases available in the Human Protein Atlas (HPA) (http://www.proteinatlas.org/). ${ }^{33}$ In particular, MD proteins were compared with: (i) the human specific proteome of 32 tissues, summing up "tissue enriched", "group enriched" and "tissue enhanced" gene categories; (ii) the housekeeping proteome (proteins detected in all tissues); and (iii) the renal cancer proteome, considering only the proteins detected in at least $80 \%$ of the HPA analysed patient tissues.

\section{Results and discussion}

\section{Protocol setup}

For the optimization of the digestion protocol, we pooled MD isolated from ANK tissues of 11 patients in order to eliminate inter-individual differences. Then we subjected aliquots of $100 \mu \mathrm{g}$ of proteins to the three protocols, and analyzed them by LC-MS/MS.

In order to select the best protocol, we took into consideration: (i) the number of total proteins identified by the Mascot search engine; (ii) the amount of hydrophobic proteins on the basis of the hydrophobicity score, GRAVY index (assigned by ProtParam http://web.expasy.org/protparam/); and (iii) the percentage of membrane proteins (classification assigned by LocDB and confirmed by TMHMM 2.0).

We first tested an adapted version of FASP digestion, already used for the MS analysis of membrane proteins (hereafter named "Protocol 1") (Table 2). ${ }^{23}$ FASP is a method that combines strong detergents for universal solubilization with efficient pre-digestion 'clean up' of the proteome in order to obtain purified peptides, avoiding the disadvantages of the gel format. ${ }^{22}$ The main feature of Protocol 1 is the lysis of MD, performed by a $30 \mathrm{~min}$ incubation in lysis RIPA buffer. The resulting analysis with LC-MS/MS led to the identification of only 32 proteins with a few signals of low intensity shown by the base peak chromatogram (ESI, $\dagger$ Fig. S1).

Due to the peculiar lipid composition of MD, we introduced a step of protein delipidation and precipitation with tri- $n$-butylphosphate, acetone, and methanol. ${ }^{21}$ This pretreatment ensured the highest protein recovery, according to Shevchenko and 


\begin{tabular}{|c|c|c|c|c|c|c|}
\hline & \multicolumn{6}{|c|}{ Protocol \# } \\
\hline & \multicolumn{2}{|c|}{1} & \multicolumn{2}{|c|}{2} & \multicolumn{2}{|c|}{3} \\
\hline & ND & $\mathrm{D}$ & ND & D & ND & D \\
\hline $\begin{array}{l}\text { Identified } \\
\text { proteins, } \mathrm{N}\end{array}$ & 32 & 103 & 199 & 292 & 170 & 342 \\
\hline $\begin{array}{l}\text { Hydrophobic } \\
\text { proteins, N (\%) }\end{array}$ & $20(63)$ & $53(52)$ & $101(51)$ & $157(54)$ & $93(55)$ & $188(55)$ \\
\hline $\begin{array}{l}\text { Membrane } \\
\text { proteins, N (\%) }\end{array}$ & 27 (84) & $72(70)$ & $121(61)$ & $190(65)$ & 117 (69) & $222(65)$ \\
\hline $\begin{array}{l}\text { Transmembrane } \\
\text { proteins (\%) }\end{array}$ & & & & & & \\
\hline $\begin{array}{l}\square \quad \begin{array}{l}\text { Peripheral } \\
\text { proteins (\%) }\end{array}\end{array}$ & & & & & & 10 \\
\hline $\begin{array}{l}\square \quad \text { Lipid-anchored } \\
\text { proteins (\%) }\end{array}$ & & & & & & \\
\hline
\end{tabular}

Fig. 1 Summary of the performance of the three FASP protocols tested in this study. Total number of identified proteins, hydrophobic and membrane proteins, and the percentage of transmembrane, peripheral, and lipid-anchored (GPI- and others) proteins are shown. ND, not-delipidated; D, delipidated.

colleagues. ${ }^{34}$ Using delipidation followed by Protocol 1, 103 proteins were identified (Fig. 1), a number still lower than in our previous study (286 proteins). ${ }^{23}$ We then tested another protocol (Protocol 2), by adding $\mathrm{NaCl}$ washing, in order to increase the recovery of hydrophobic peptides, and one acidification step with $0.1 \%$ TFA, on both delipidated and non-delipidated samples (Table 2). These settings determined an increased, yet not fully satisfactory, recovery of proteins (Fig. 1).

The conditions were then further modified in Protocol 3, which, unlike the other protocols, involves the use of SDS buffer and urea (Table 2). In particular, we performed all washings with $8 \mathrm{M}$ urea, which should fully wash out detergents from membrane proteins. ${ }^{35}$ When applied without delipidation, this protocol led to the identification of 170 proteins, of which only $23 \%$ were transmembrane proteins (Fig. 1). This could be due to the lipids-SDS interaction: as a consequence, the SDS cannot be efficiently removed by the filter, interfering with the MS analysis (ESI, $\uparrow$ Fig. S1). Moreover, the filter may retain some lipid components, together with hydrophobic lipid-bound proteins.

Conversely, Protocol 3 coupled to delipidation was the most efficient way to identify proteins in MD. In fact, firstly, the introduction of the delipidation step resulted in a significant increase in the yield of total protein identification $(N=342)$. Secondly, the total number of membrane proteins greatly increased $(N=222)$, boosting the percentage of transmembrane proteins to $50 \%$.

These results may depend on the depletion of the lipid components, which likely enables the "release" of transmembrane proteins. Once freed, they become more suitable for tryptic digestion, thus generating peptides that can be eluted through a $30-k D a$ cut-off FASP filter. ${ }^{36}$

\section{LC-MS protein identification and label-free quantification}

The optimized protocol was implemented to perform the comparison between RCC and ANK MD. In fact, we speculated that the delipidation step could eliminate some differences in protein identification due to the different lipid composition (data not shown), making the comparative proteomic analysis more reliable. We first evaluated the recovery after MD delipidation as shown in the ESI, $\dagger$ Fig. S2. The extraction of ANK and RCC MD proteins after delipidation is reproducible, and the protein profiles were comparable with the non-delipidated ones (ESI, $\dagger$ Fig. S2). Proteins of microdomain-enriched fractions prepared from 5 paired samples of RCC and ANK tissues were pooled and analyzed. Identification was accepted with at least one unique peptide exceeding the Mascot score of identity cutoff, in order to ensure a better understanding of MD proteomes. Exploiting the powerful peak detection of the Progenesis algorithm (used during the label-free protein expression evaluation), and applying the above detailed criteria, MS/MS analysis after FASP digestion led to the identification of 742 proteins in ANK and 721 in ccRCC MD. Overall, more than 800 protein species were identified; their full details, including scores and the number of matched peptides, are given in the ESI, $\dagger$ Tables S1 and S2.

The molecular characteristics of the identified proteins were assessed by bioinformatics and prediction tools. ${ }^{37}$ The results showed that the majority of the identified proteins $(53.1 \%$ and $52.6 \%$ in ANK and RCC, respectively) were membrane-associated, with about $58 \%$ of them being transmembrane proteins (ESI, $\dagger$ Tables S1 and S2). Many of them were typical raft proteins, such as caveolins (1 and 2), flotillins, aquaporin-1, prohibitins, VDAC1 and Thy-1. Comparing our list of total MD identified proteins to RaftProt, a recently published Mammalian Lipid raft Proteome Database (http://lipid-raft-database.di.uq.edu.au/index.html), ${ }^{38}$ $580(72 \%)$ were classified as human lipid raft associated proteins and $394(49 \%)$ as High Confidence lipid raft proteins. Moreover, we investigated whether protein sequences contained sites for post-translational modifications such as glypiation, palmitoylation, and myristoylation, using prediction algorithms. They assigned putative myristoylation sites to about $15 \%$ of total identified membrane proteins and GPI anchoring to 5\% of them. Much more frequent, about $44 \%$, was the prediction of palmitoylation sites. Additionally, STRING analysis classified 


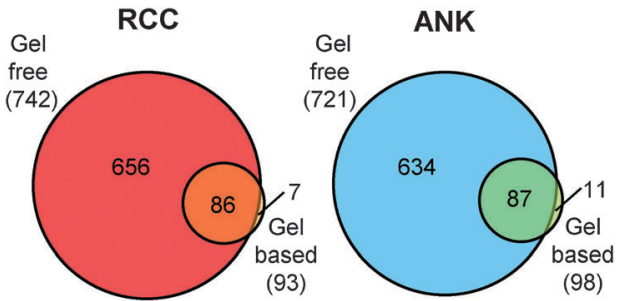

Fig. 2 Venn diagram of protein species identified in RCC and ANK MD using two different analytical approaches. The comparison of protein identification data obtained in the present - gel free - study and in the previous - gel based - one is shown. ${ }^{20}$

$67 \%$ of proteins as constituents of protein complexes. These findings are intriguing, because both such post-translational modification and protein-protein interactions are likely to determine a - possibly reversible - association with the membrane MD of otherwise soluble proteins, allowing for their dynamic binding to microdomains. ${ }^{39}$ After applying these tools for the prediction of - direct or indirect - membrane interactions, only 79 proteins $(9.8 \%)$ were left out.

These results are in good agreement with a recently published work, concerning chicken inner ear membrane MD proteomics. ${ }^{37}$ Mass spectrometry of MD fractions identified over 600 putative raft proteins, and most of them were predicted as membraneassociated and involved in trafficking and metabolism.

Very few other papers broached tissue MD proteomics. In particular, a study by $\mathrm{Yu}$ et al. adopted a "tube-gel" protein digestion label-free shotgun proteomic strategy to quantify raft proteins in the neonatal mouse brain - about 200 raft proteins were identified from a single sample, thus defining a core proteome qualitatively quite similar to ours and previous ones. ${ }^{37,40,41}$

This highlights the common modularity features of $\mathrm{MD}$, as a quite stable structure that plays a comparable role in different settings. ${ }^{40}$ In fact, membrane $\mathrm{MD}$, on the one hand, are highly dynamic, with protein (and lipid) components shuttling rapidly between raft and non-raft membranes, and on the other hand, present a fixed and common proteomic core, accounting for their structural and specific characteristics.

In our previous work, we analyzed the same RCC and ANK MD samples by a gel based method (Table 1). ${ }^{20}$ The present optimized gel-free approach seems to be more suitable for the study of membrane microdomains, providing a higher number of total identified proteins (742 vs. 98 in ANK MD and 721 vs. 93 in RCC MD). It is noteworthy that more than $88 \%$ of the proteins identified with the gel-based approach were also found using the shotgun proteomic strategy (Fig. 2), confirming their localization in the MD.

We assessed the tissue specificity of the MD proteome, comparing the new list of MD proteins with the Human Protein Atlas database (HPA) ${ }^{33}$ - a comparison with the human tissuespecific proteomes of 32 different tissues showed a peak matching with kidney-specific ones (Fig. 3). Moreover, 30.5\% of proteins identified in RCC MD were already detected in HPA renal cancer tissue microarrays. It has to be stressed that subcellular fractionation, and in particular MD purification, greatly enhances the possibility to identify low-abundance proteins, undetectable in the whole tissue. Several protein classes (i.e. G proteins, RAS-related proteins, components of the vacuolar ATPase-synthase complex, etc.) cannot indeed be tissue specific because they are typical for the MD proteome, regardless of their tissue localization. ${ }^{40}$

We then evaluated the differential proteome by label-free quantification, considering proteins to be "up-" or "down-regulated" when the ratio was, respectively, higher than 1.50 and lower than $0.67 .^{22,26}$ Applying these criteria to 657 quantified protein species, 170 (25.9\%) were classified as "up" and 126 (19.2\%) as "down” in RCC MD (ESI, $\dagger$ Table S1).

The differential proteins ("up" and "down") were correlated with subcellular localization (by LocDB) and molecular function (by Panther) (Fig. 4). The majority of "down" proteins were membrane-associated (70.6\%) (Fig. 4A); this result could be

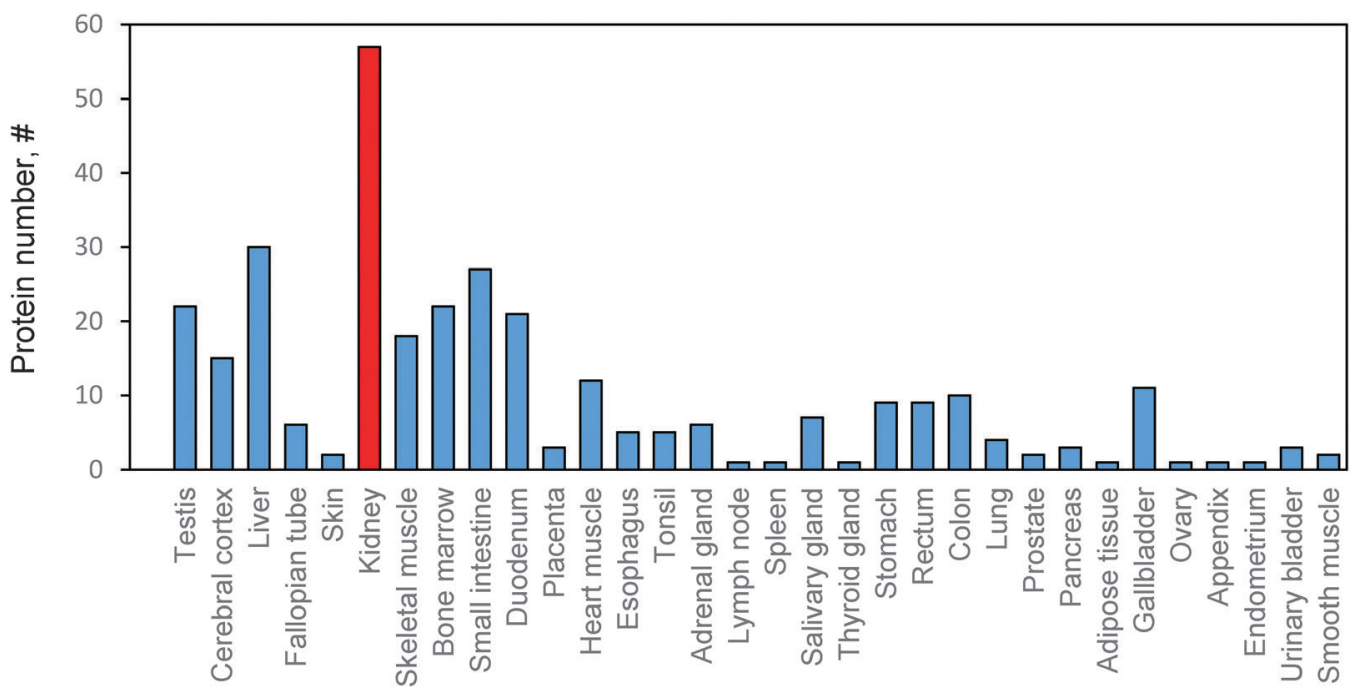

Fig. 3 Tissue specificity analysis. The number of MD proteins matched with the human tissue specific proteomes of 32 different tissues is shown. 
A
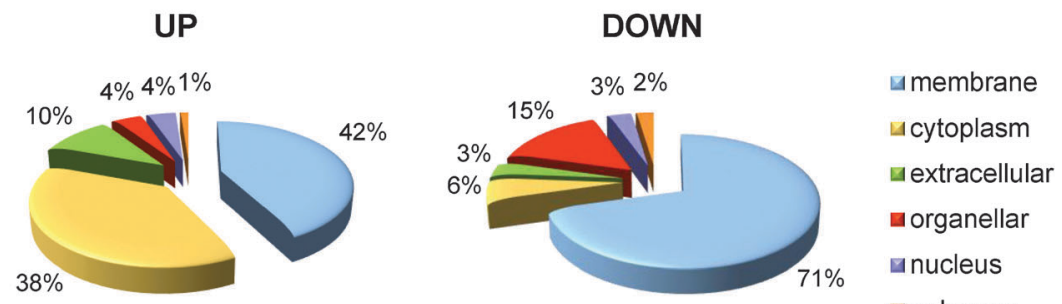

⿶unknown

B

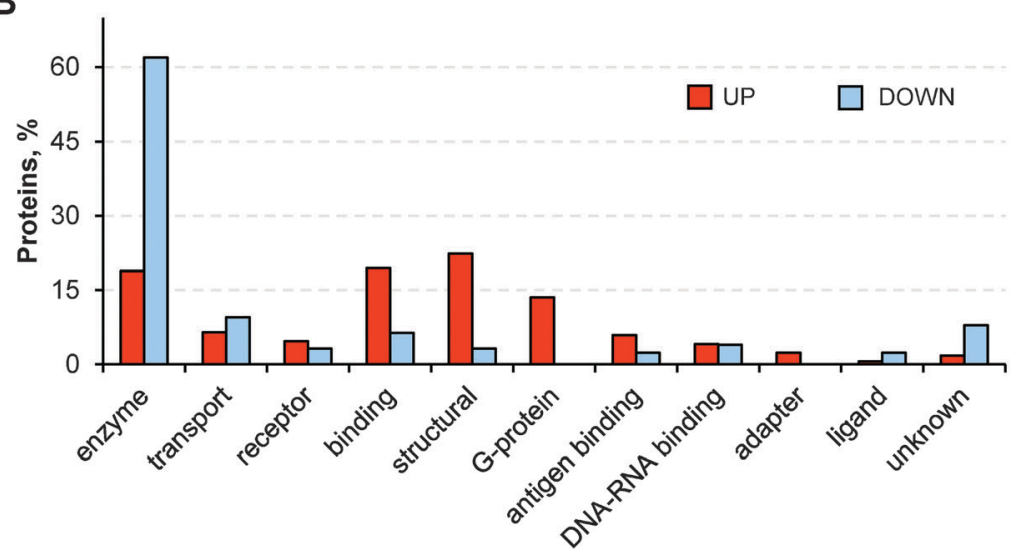

Fig. 4 Subcellular localization and molecular functions of the RCC differential proteins, classified into "UP" and "DOWN". (A) Pie charts representing the cellular localization of the differential proteins. (B) Histogram representation of the percentage of differential proteins in main molecular functions.

dependent on the process of de-differentiation typical for cancer cells, which lose their tubular epithelial specialization. In fact, among "down" proteins, we found aquaporin-1 (AQP1), a water-channel that is considered a kidney differentiation marker, ${ }^{42}$ $\mathrm{Na}^{+} /$glucose co-transporters 2 and 5, involved in glucose reabsorption by proximal tubule cells, and renal dipeptidase (DPEP-1), a zinc-dependent membrane metalloprotease. ${ }^{43}$

In contrast, the "up" proteins are found to be partially membrane $(42.3 \%)$ and partially cytoplasmic proteins $(38.2 \%)$ (Fig. 4A). It has to be underlined that some cytosolic proteins may associate with the plasma membrane and MD, through cytoskeletal components. ${ }^{44}$ Several cytoskeleton associated-proteins, such as ezrin, radixin and moesin, members of the ezrin-radixinmoesin (ERM) family, involved in cancer progression, ${ }^{45}$ are in fact increased in RCC MD. Interestingly, focusing on post-translational modifications, the predicted palmitoylation sites appeared nearly doubled (from 42.5 to $71 \%$ ) among "up", compared to "down" proteins. It is tempting to speculate that this behavior is driven by a modification of the RCC MD lipid composition, thus allowing cancer cells to deliver new proteins, perhaps involved in aberrant signaling events, towards MD. The elucidation of this hypothesis deserves further investigation.

By analyzing this list of proteins using Panther, an on-line tool for the classification of genes according to the Gene ontology classes, we obtained the picture shown in Fig. 4B. From a functional point of view, the presence of neoplasm seems to increase some peculiar protein classes involved in signaling and adhesion, typical MD-associated processes. In fact, G proteins, structural, and binding proteins (e.g., flotillins, tubulins, annexins, and caveolins), were more abundant in RCC MD, compared to ANK.

It has to be underlined that most of differential proteins in our previous gel-based study were confirmed here, after label free quantification, for example, Basigin, DPEP1, AQP1, and caveolin-1 (ESI, $\uparrow$ Table S1). This result may indeed represent a preliminary validation.

\section{Validation of differential RCC MD protein content by immunoblotting analysis}

Relative quantification results obtained by the label-free approach were verified by immunoblotting of three differential proteins, carbonic anhydrase 2 (CA2), annexin A2 (ANXA2), and aminopeptidase $\mathrm{N}$ (CD13), comparing the signal intensity in different subcellular fractions prepared from ANK and RCC (Fig. 5).

The choice of these three proteins was firstly based on their significantly high or low RCC/ANK ratio (CA2, 2.54; ANXA2, 1.97; CD13, 0.37) obtained after label-free quantification. Secondly, ANXA2 and CD13 were already reported as MD associated, and listed as High Confidence Raft Proteins in the RaftProt database. ${ }^{38}$ On the other hand, CA2 is a typical cytosolic enzyme, responsible for more than $95 \%$ of the total kidney carbonic anhydrase activity ${ }^{46}$ and it is not usually described as a MD bound protein.

WB results regarding ANXA2 confirmed label-free quantification, being up-regulated in RCC samples, compared to ANK. This difference is higher at the MD level than in whole lysates, suggesting the occurrence of an altered subcellular localization 


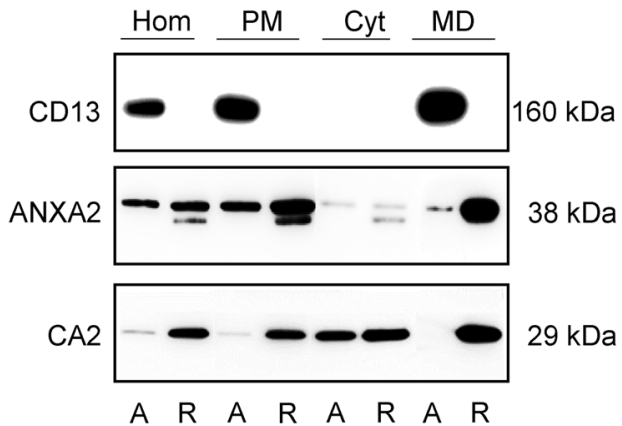

Fig. 5 Validation of the differential content of carbonic anhydrase 2 (CA2) annexin A2 (ANXA2) and aminopeptidase N (CD13) in RCC MD. (A) The abundance of some differential proteins was assessed in ANK (A) and RCC (R) MD, compared with the whole lysate (Hom) and plasma membrane-enriched fractions (PM) from which MD were prepared, and with the cytosolic fractions (Cyt), by immunoblotting with specific antibodies. Seven $\mu \mathrm{g}$ of proteins of Hom, PM and Cyt, and $3 \mu \mathrm{g}$ of proteins of MD were loaded on SDS-PAGE gels. One (out of 3) representative case is shown.

in the RCC tissue. ANXA2 is actually considered a marker of several cancer cells (reviewed in ref. 47), and its overexpression in RCC has already been reported. ${ }^{48}$ Its key role in the organization of lipid raft signaling domains by binding to membrane phospholipids, under physiological conditions, was also described. ${ }^{49}$ A very recent paper $^{50}$ outlines the regulatory role of ANXA2 in RCC cell motility and the change in ANXA2 localization from cytoplasm to membranes in the RCC tissue (by immunohistochemistry), supporting our findings.

Aminopeptidase $\mathrm{N}$ is a transmembrane zinc-dependent ectoenzyme, expressed by various tissues, including the kidney. ${ }^{51}$ Besides its peptidase activity, it is physiologically involved in endocytosis and signaling. ${ }^{52}$ CD13 is down-regulated in RCC $\mathrm{MD}$, as determined by label-free analysis; accordingly, its signal was undetectable in RCC subfractions, while highly enriched in ANK MD, compared to the homogenate and total plasma membrane fractions. Although this protein is usually reported as up-regulated in many cancers, such as mesenchymal tumors, breast, ovarian and colon cancer (reviewed in ref. 53 and 54), some studies performed on RCC tissues showed a reduction of CD13 levels, compared to ANK, both by immunohistochemistry ${ }^{55}$ and by the measure of its surface enzymatic activity. ${ }^{56}$

CA2 appeared more abundant in all RCC subcellular fractions, and its signal was particularly and specifically strong at the RCC MD level, while undetectable in the corresponding ANK lane, confirming once again the data obtained by label-free quantification. These data suggest a possible tumor-dependent mis-localization of CA2 in RCC MD. Interestingly, an increased expression of CA2 has been reported in the neovessel endothelium of several tumors, such as melanoma and esophageal, renal, and lung cancer, but not in the corresponding healthy vascular cells. ${ }^{57}$ Since we prepared fractions from whole RCC tissue, the signal intensity detected in MD may indeed be derived from tumoral neovessels.

Overall, the validation of these three proteins further supports the potency of label-free MS approach.

\section{Conclusions}

In conclusion, our results show the importance of setting up a specific protocol for the proteomic analysis of membrane proteins, according to the different molecular features of the sample. Moreover, our data confirm that the sensitivity of proteomic profiling can be significantly enhanced by focusing on highly enriched subcellular fractions, such as MD. The optimization of all analytical steps, from sample pre-fractionation and preparation to the MS analysis and label-free quantification, provided us with a large panel of differential RCC MD proteins, among which tumor biomarkers may be looked for.

\section{Acknowledgements}

This work was supported by grants from FIRB: Rete Nazionale per lo studio del proteoma umano (no. RBRN07BMCT).

\section{References}

1 B. Ljungberg, S. C. Campbell, H. Y. Choi, D. Jacqmin, J. E. Lee, S. Weikert and L. A. Kiemeney, Eur. Urol., 2011, 60, 615-621.

2 P. A. Godley and M. Taylor, Curr. Opin. Oncol., 2001, 13, 199-203.

3 B. Ljungberg, Curr. Urol. Rep., 2013, 14, 19-25.

4 F. Raimondo, S. Corbetta, C. Chinello, M. Pitto and F. Magni, Expert Rev. Proteomics, 2014, 11, 503-514.

5 H. D. Shukla, P. Vaitiekunas and R. J. Cotter, Proteomics, 2012, 12, 3085-30104.

6 A. Kumar, D. Baycin-Hizal, J. Shiloach, M. A. Bowen and M. J. Betenbaugh, Proteomics: Clin. Appl., 2015, 9, 33-47.

7 F. Raimondo, P. Ceppi, K. Guidi, M. Masserini, C. Foletti and M. Pitto, Expert Rev. Proteomics, 2005, 2, 793-807.

8 K. A. Jahn, Y. Su and F. Braet, World J. Gastroenterol., 2011, 17, 681-690.

9 A. Hryniewicz-Jankowska, K. Augoff, A. Biernatowska, J. Podkalicka and A. F. Sikorski, Biochim. Biophys. Acta, 2014, 1845, 155-165.

10 F. Mollinedo and C. Gajate, Adv. Biol. Regul., 2015, 57, 130-146.

11 K. L. Inder, M. Davis and M. M. Hill, Mol. BioSyst., 2013, 9, 330-338.

12 S. Staubach and F. G. Hanisch, Expert Rev. Proteomics, 2011, 8, 263-277.

13 S. Minogue and M. G. Waugh, Biol. Cell., 2012, 104, 618-627.

14 S. K. Patra, Biochim. Biophys. Acta, Rev. Cancer, 2008, 1785, 182-206.

15 C. Lin, Z. Wu, X. Lin, C. Yu, T. Shi, Y. Zeng, X. Wang, J. Li and L. Song, Clin. Cancer Res., 2010, 17, 3089-3099.

16 L. Belov, J. Zhou and R. I. Christopherson, Int. J. Mol. Sci., 2010, 12, 78-113.

17 C. V. Recktenwald, R. Lichtenfels, J. Wulfaenger, A. Müller, S. P. Dressler and B. Seliger, Proteomics, 2015, 15, 77-88.

18 Y. Nagashima, Y. Inayama, Y. Kato, N. Sakai, H. Kanno, I. Aoki and M. Yao, Pathol. Int., 2004, 54, 377-386. 
19 S. A. Fuhrman, L. C. Lasky and C. Limas, Am. J. Surg. Pathol., 1982, 6, 655-663.

20 F. Raimondo, L. Morosi, C. Chinello, R. Perego, C. Bianchi, G. Albo, S. Ferrero, F. Rocco, F. Magni and M. Pitto, Mol. BioSyst., 2012, 8, 1007-1016.

21 R. Mastro and M. Hall, Anal. Biochem., 1999, 273, 313-315.

22 J. R. Wiśniewski, A. Zougman, N. Nagaraj and M. Mann, Nat. Methods, 2009, 6, 359-362.

23 F. Raimondo, S. Corbetta, L. Morosi, C. Chinello, E. Gianazza, G. Castoldi, C. Di Gioia, C. Bombardi, A. Stella, C. Battaglia, C. Bianchi, F. Magni and M. Pitto, Mol. BioSyst., 2013, 9, 1139-1146.

24 E. Gianazza, C. Chinello, V. Mainini, M. Cazzaniga, V. Squeo, G. Albo, S. Signorini, S. S. Di Pierro, S. Ferrero, S. Nicolardi, Y. E. van der Burgt, A. M. Deelder and F. Magni, J. Proteomics, 2012, 76, 125-140.

25 C. Chinello, M. Cazzaniga, G. De Sio, A. J. Smith, E. Gianazza, A. Grasso, F. Rocco, S. Signorini, M. Grasso, S. Bosari, I. Zoppis, M. Dakna, Y. E. van der Burgt, G. Mauri and F. Magni, PLoS One, 2014, 9, e106684.

26 X. Liu, C. Chinello, L. Musante, M. Cazzaniga, D. Tataruch, G. Calzaferri, A. J. Smith, G. De Sio, F. Magni, H. Zou and H. Holthofer, Proteomics: Clin. Appl., 2014, DOI: 10.1002/ prca.201400085.

27 E. L. Sonnhammer, G. von Heijne and A. Krogh, Proc. Int. Conf. Intell. Syst. Mol. Biol., 1998, 6, 175-182.

28 A. Krogh, B. Larsson, G. von Heijne and E. L. Sonnhammer, J. Mol. Biol., 2001, 305, 567-580.

29 J. Ren, L. Wen, X. Gao, C. Jin, Y. Xue and X. Yao, Protein Eng., Des. Sel., 2008, 21, 639-644.

30 B. Eisenhaber, P. Bork and F. Eisenhaber, J. Mol. Biol., 1999, 292, 741-758.

31 G. Bologna, C. Yvon, S. Duvaud and A. L. Veuthey, Proteomics, 2004, 4, 1626-1632.

32 A. Franceschini, D. Szklarczyk, M. Kuhn, M. Simonovic, A. Roth, J. Lin, P. Minquez, P. Bork, C. von Mering and L. J. Jensen, Nucleic Acids Res., 2013, 41, D808-D815.

33 M. Uhlén, L. Fagerberg, B. M. Hallström, C. Lindskog, P. Oksvold, A. Mardinoglu, A. Sivertsson, C. Kampf, E. Sjöstedt, A. Asplund, I. Olsson, K. Edlund, E. Lundberg, S. Navani, C. A. Szigyarto, J. Odeberg, D. Djureinovic, J. O. Takanen, S. Hober, T. Alm, P. H. Edqvist, H. Berling, H. Tegel, J. Mulder, J. Rockberg, P. Nilsson, J. M. Schwenk, M. Hamsten, K. von Feilitzen, M. Forsberg, L. Persson, F. Johansson, M. Zwahlen, G. von Heijne, J. Nielsen and F. Pontén, Science, 2015, 347, 1260419.1-1260419.9.

34 G. Shevchenko, M. O. D. Sjodin, D. Malmstrom, M. Wetterhall and J. Bergquist, J. Proteome Res., 2010, 9, 3903-3911.

35 N. Nagaraj, A. Lu, M. Mann and J. R. Wisniewski, J. Proteome Res., 2008, 7, 5028-5032.

36 W. Dormeyer, D. van Hoof, C. L. Mummery, J. Krijgsveld and A. J. Heck, Proteomics, 2008, 8, 4036-4053.
37 P. V. Thomas, A. L. Cheng, C. C. Colby, L. Liu, C. K. Patel, L. Josephs and R. K. Duncan, J. Proteomics, 2014, 103, 178-193.

38 A. Shah, D. Chen, A. R. Boda, L. J. Foster, M. J. Davis and M. M. Hill, Nucleic Acids Res., 2015, 43, D335-D338.

39 J. E. Smotrys and M. E. Linder, Annu. Rev. Biochem., 2004, 73, 559-587.

40 F. Raimondo, P. Ceppi, K. Guidi, M. Masserini, C. Foletti and M. Pitto, Expert Rev. Proteomics, 2005, 2, 793-807.

41 H. Yu, B. Wakim, M. Li, B. Halligan, G. S. Tint and S. B. Patel, Proteome Sci., 2007, 5, 17.

42 D. Ticozzi-Valerio, F. Raimondo, M. Pitto, F. Rocco, S. Bosari, R. Perego, C. Sarto, A. Di Fonzo, N. Bosso, P. Mocarelli, M. Galli-Kienle and F. Magni, Proteomics: Clin. Appl., 2007, 1, 588-597.

43 Y. Toiyama, Y. Inoue, H. Yasuda, S. Saigusa, T. Yokoe, Y. Okugawa, K. Tanaka, C. Miki and M. Kusunoki, J. Gastroenterol., 2011, 46, 153-163.

44 G. R. Chichili and W. Rodgers, Cell. Mol. Life Sci., 2009, 66, 2319-2328.

45 J. Clucas and F. Valderrama, J. Cell Sci., 2014, 127, 267-275.

46 J. M. Purkerson and G. J. Schwartz, Kidney Int., 2007, 71, 103-115.

47 A. Bharadwaj, M. Bydoun, R. Holloway and D. Waisman, Int. J. Mol. Sci., 2013, 14, 6259-6305.

48 F. Raimondo, C. Salemi, C. Chinello, D. Fumagalli, L. Morosi, F. Rocco, S. Ferrero, R. Perego, C. Bianchi, C. Sarto, M. Pitto, P. Brambilla and F. Magni, Mol. BioSyst., 2012, 8, 1040-1051.

49 M. Valapala and J. K. Vishwanatha, J. Biol. Chem., 2011, 286, 30911-30925.

50 S. F. Yang, H. L. Hsu, T. K. Chao, C. J. Hsiao, Y. F. Lin and C. W. Cheng, Urol. Oncol., 2015, 33, 11-21.

51 G. Pathuri, V. Madka, A. F. Hedrick, S. A. Lightfoot, V. Awasthi, B. D. Jr Cowley, C. V. Rao and H. Gali, Mol. Pharmaceutics, 2014, 11, 2948-2953.

52 N. Petrovic, W. Schacke, J. R. Gahagan, C. A. O’Conor, B. Winnicka, R. E. Conway, P. Mina-Osorio and L. H. Shapiro, Blood, 2007, 110, 142-150.

53 Y. Luan and W. Xu, Curr. Med. Chem., 2007, 14, 639-647.

54 M. Wickström, R. Larsson, P. Nygren and J. Gullbo, Cancer Sci., 2011, 102, 501-508.

55 K. Ishii, S. Usui, H. Yamamoto, Y. Sugimura, M. Tatematsu and K. Hirano, J. Biochem., 2001, 129, 253-258.

56 A. Varona, L. Blanco, J. I. Lopez, J. Gil, E. Agirregoitia, J. Irazusta and G. Larrinaga, Am. J. Physiol. Renal Physiol., 2007, 292, 780-788.

57 K. Yoshiura, T. Nakaoka, T. Nishishita, K. Sato, A. Yamamoto, S. Shimada, T. Saida, Y. Kawakami, T. A. Takahashi, H. Fukuda, S. Imajoh-Ohmi, N. Oyaizu and N. Yamashita, Clin. Cancer Res., 2005, 11, 8201-8207. 